\title{
Detonation propagation along percolating cluster in composite explosives
}

\author{
Vitaly Komarov ${ }^{1}$ Gennady Sakovich ${ }^{1}$, Nikolai Popok $^{2}$, Maxim Kazutin ${ }^{1}$ and Nikolai Kozyrev ${ }^{1}$ \\ ${ }^{1}$ Institute for Problems of Chemical and Energetic Technologies, SB RAS, Biysk, Russia \\ ${ }^{2}$ AO Federal Research \& Production Center ALTAI, Biysk, Russia
}

\begin{abstract}
The detonation performance of melt-cast plastic-bonded explosives (PBXs) based on high melting explosive octogen (HMX) was studied in the paper. It has been found that the detonation velocity strongly depends from the dispersion distribution of HMX particles: it changes from 7800 to $8700 \mathrm{~m} / \mathrm{s}$. We explain this by the possibility of detonation propagation in PBX through different mechanisms, including detonation front propagation along a percolating cluster formed by filler particles. Thus, varying the particle size distribution can bring about one detonation mechanism or another and hence control the energy release dynamics of melt-cast PBXs to attain high efficiency in practice. Experimental results confirm the assumptions.
\end{abstract}

\section{Introduction}

Plastic-bonded explosives (PBX) structurally represent mixed high-order explosives with a polymeric binder. Due to heterogeneity PBXs can be defined as a 'solidsuspension' in which explosive crystals (solid phase) are distributed in a continuous polymeric matrix (dispersed phase).

Depending on the volume polymer fraction, PBX charges can be shaped by pressing, extrusion, or casting; the charge shape is secured (cured) by chemical crosslinking or transition to the high- elasticity state upon cooling (in case thermoplastic polymers are used). There is also a curing system in use that is based on dissolving the polymer in a plasticizer to generate a high-viscosity matrix (plastisol PBX). The hexogen (RDX) and high melting explosive octogen (HMX) are frequently used as the high-order filler of conventional PBXs. The polymeric binder is typically a homogeneous multicomponent system comprising a polymeric base, plasticizers, processing and performance additives, etc. Many PBXs contain aluminum as the energetic additive [1-3].

All polymeric binders used in PBX compositions can be classified into two types: inert binders (inert polymer binder - IPB) not involving in exothermic explosion reactions and active binders (active polymer binder APB) capable of self-explosion and those being oxidizers towards PBX components. This classification is conditional: fluorinated polymers in PBXs containing no metal fuel are inert, whereas those in aluminized PBXs should be referred to the APB because their decomposition products when interacting with $\mathrm{Al}$ contribute considerably to the explosion energy output.
PBXs are widely used because they have superb mechanical properties, a low porosity, are able to fill in complex forms, and exhibit a reduced sensitivity to mechanical stimuli. The listed advantages are mostly inherent in melt-cast PBXs that are characterized by a relatively high content of the binder. Their sensitivity is low because the polymeric matrix is continuous and elastic and is capable of uniformly distributing external mechanical energy, thereby preventing the detonation progression.

The global tendency to mitigating the risks when handling and using explosives determines the increasing proportion of PBXs in the nomenclature of practical formulations. For instance, fluorinated matrices filled with powdered triaminotrinitrobenzene (TATB) are modern standards of safe explosives such as PBX 9502 (95 wt.\% TATB, 5\% fluorinated binder) and LX-17-0 ( $92.5 \%$ TATB and $7.5 \%$ chlorofluoropolymer binder) [12].

The firther improvement in explosive formulations is associated with the development of melt-cast PBXs based on an APB. New high-energy-density polymers and plasticizers have now emerged that contain nitrate groups (Poly-GLIN, poly-NIMMO, PGN), azide groups (GAP, BAMO, AMMO) [4], azole moieties [5], etc. PBXs with a high content of the APB can ensure safety and casting properties with a minimum reduction in the detonation performance compared to more powerful pressed formulations.

The approach to developing melt-cast PBXs are typically attributed to minimizing the binder content where a possibility remains to shape charges by the casting process, and the practice demonstrates that the greater the content of the high-order filler, the better the detonation performance.

Corresponding author: iphet@rambler.ru 
The casting properties of the suspension are governed by its viscosity which depends on the amount, shape and size of filler particles [6], interfacial energy, etc. The known method for reducing the viscosity at a high filler content is to use the bimodal grain size of the solid phase [6-7]. Thus, the maximum filler content and acceptable viscosity can be optimized under other equal conditions by down-selecting a filler fractional composition which will eventually be determinate for one or another system. In doing so, the practical efficiency attributes such as brisance, acceleration ability and blast effect are accepted de facto and considered a-priori to be maximum for the thus-optimized system.

In our previous studies on melt-cast HMX-based PBX composites with an APB [8-12] presented herein, we did not aim to provide the maximum filler content and confined it to no less than 25 vol.\%. The purpose on this paper is to show the relationships between detonation velocity, acceleration ability, and filler particle size while preserving casting properties.

\section{Experimental part}

\subsection{Materials}

We examined a melt-cast PBXs based on an APB - a homogeneous explosive system - which is a plasticized methylpolyvinyltetrazole polymer (CHNO-type) having a density of about $1.5 \mathrm{~g} / \mathrm{cm}^{3}$. The binder's own detonation velocity was $7200 \mathrm{~m} / \mathrm{s}$ for a charge with diameter of $25 \mathrm{~mm}$ in a steel tube ; the critical diameter of detonation was over $20 \mathrm{~mm}$. The filler was HMX (Russian production) with different particle sizes, whose calculated threshold of the detonation velocity was 9160 $\mathrm{m} / \mathrm{s}$ [8] and the density was $1.91 \mathrm{~g} / \mathrm{cm}^{3}$. Micron-sized aluminum powders (Al, brand «ASD, RUSAL, Russia) with spherical particles were used as the energetic additive. A curing agent in the concentration of 0.5 vol. $\%$ was incorporated into all composite explosives. The explosive blends were mixed by hand, then cured, and loaded into plastic tubes and kept under specified conditions until they were completely cured.

\subsection{Experimental setup}

The detonation velocity $D$ was measured by discrete point system, based on the short circuit of ionization sensors, the signal from which is transmitted to a recording oscilloscope with a frequency of $50 \mathrm{MHz}$. Shellless or plastic encapsulated charges of 20-25 mm in diameter and 50-100 $\mathrm{mm}$ long were used. Distance between two sensors was $20-25 \mathrm{~mm}$. A booster charge with the same diameter and a height of $10 \mathrm{~mm}$ was used for initiation. The booster charge's own detonation velocity was $7500 \mathrm{~m} / \mathrm{s}$. The first sensor was at a distance of no more than $25 \mathrm{~mm}$ from the initiation plane. The measurement error was $\pm 50 \mathrm{~m} / \mathrm{s}$. Typically, at least three parallel tests were run, and the average of three was the measurement result.

The acceleration ability was determined by the endface throwing method in which a $25-\mathrm{mm}$ diameter steel plate of $2.5 \mathrm{~mm}$ in thickness and $9.35 \pm 0.05 \mathrm{~g}$ in weight was thrown from the end face of a plastic shell-enclosed charge of $25-\mathrm{mm}$ in diameter and $50 \mathrm{~mm}$ long. The acceleration ability was expressed as the plate flying velocity $\omega(\mathrm{m} / \mathrm{s})$ measured by discrete point system, similar to that described above. The distance between the contact sensors was $300 \mathrm{~mm}$ to minimize the influence of the overclocking area on the result of measuring. The measuring system error was not in excess of $\pm 50 \mathrm{~m} / \mathrm{s}$. Two to three parallel measurements were done and the results were taken into account only from those tests in which the thrown plate did not break down, as was evidenced by the way how the contact target was breached. The measurement schematic is illustrated in Figure 1.

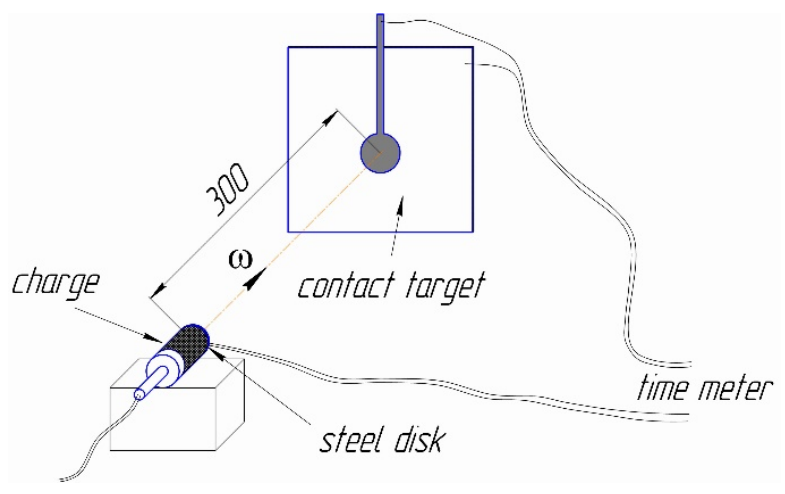

Fig. 1. Schema for the measurement of acceleration ability.

\section{Results and discussion}

\subsection{Relationship between detonation velocity and HMX particle size}

In initial experiments, the detonation velocity $D$ was examined as a function of the HMX particle size in binary PBXs such as HMX/APB. Two types of HMX was used: a coarse fraction (fraction 1) and a fine fraction (fraction 2) at a different ratio thereof. Measurements were done on charges of $25 \mathrm{~mm}$ in diameter. The test composite explosives and detonation velocity measurement results are summarized in Table 1. The average HMX particle size for fine $\left(d_{l}\right)$ and coarse $\left(d_{2}\right)$ fractions are given therein. All the composites under test retained casting properties.

It can be seen in Table 1 that the detonation velocity is dependent heavily on the component particle sizes: the obtained detonation velocity values ranged from 7800 to $8760 \mathrm{~m} / \mathrm{s}$. The following general tendencies can be deduced from the findings. When the single-fraction filler is used, the detonation velocity increases with increasing particle size (compare the test results for compositions Nos 1-3 and 6 in Table 1). Probably, this tendency is extremal in nature: if the particle size exceeds some limit, the detonation velocity declines (compositions Nos 10-11 compared to Nos 3 and 6). Further, the highest detonation velocity is achieved by using two-fraction HMX when the mean fine fraction size is below $50 \mu \mathrm{m}$ and the mean coarse fraction size is 200-300 $\mu \mathrm{m}$, in which case the optimum coarse/fine 
fraction ratio for this system is $\sim 70 / 30 \%$ (compositions Nos 5 and 8-9).

Table 1. Detonation velocity of HMX/APB composites depending on HMX particle size.

\begin{tabular}{|c|c|c|c|c|c|c|}
\hline \multirow{3}{*}{ \# } & \multicolumn{4}{|c|}{$\begin{array}{c}\text { Concentration }(\%) \text { and size of } \\
\text { HMX powder in PBX } \\
\text { compositions }\end{array}$} & \multirow{3}{*}{ APB, \% } & \multirow{3}{*}{$\begin{array}{c}D \\
\mathbf{m} / \mathbf{s}\end{array}$} \\
\hline & \multicolumn{2}{|c|}{ Fraction 1} & \multicolumn{2}{|c|}{ Fraction 2} & & \\
\hline & $\%$ & $d_{1}, \mu \mathrm{m}$ & $\%$ & $d_{2}, \mu \mathrm{m}$ & & \\
\hline 1 & - & - & 80.0 & 85 & 20.0 & 7800 \\
\hline 2 & - & - & 80.0 & 125 & 20.0 & 7760 \\
\hline 3 & - & - & 80.0 & 175 & 20.0 & 8240 \\
\hline 4 & 32.2 & 500 & 45.8 & 125 & 22.0 & 8300 \\
\hline 5 & 54.6 & 315 & 23.4 & $<50$ & 22.0 & 8560 \\
\hline 6 & 78.0 & 200 & - & - & 22.0 & 8400 \\
\hline 7 & 54.6 & 500 & 23.4 & 125 & 22.0 & 8200 \\
\hline 8 & 54.6 & 200 & 23.4 & $<50$ & 22.0 & 8460 \\
\hline 9 & 54.6 & 200 & 23.4 & $<50$ & 22.0 & 8760 \\
\hline 10 & 40.0 & 950 & 40.0 & 125 & 20.0 & 8150 \\
\hline 11 & 30.0 & 950 & 50.0 & 125 & 20.0 & 8300 \\
\hline
\end{tabular}

We explain the obtained results as follows: when the polymeric matrix is mixed with crystalline HMX, the crystals are separated by the polymeric interlayer and randomly oriented in space. The propagation of detonation along the explosive charge is defined by the filler's volume fraction $\varphi$ and the interlayer ability to transmit detonation from the crystal to crystal [8-10]. The propagation velocity in local areas is not monotonic, as is illustratively shown in Figure 2, and is defined by the volume fraction $\varphi_{i}$ and detonation velocity $D_{0 i}$ of each component:

$$
D=\sum_{i=1}^{n} \varphi_{i} *\left(\sum_{i=1}^{n} \frac{\varphi_{i}}{D_{0 i}}\right)^{-1}
$$

where $\varphi_{i}$ is the volume fraction of the $i$ th component; $D_{0 i}$ is the detonation velocity (front transmit velocity) along the $i$ th component.

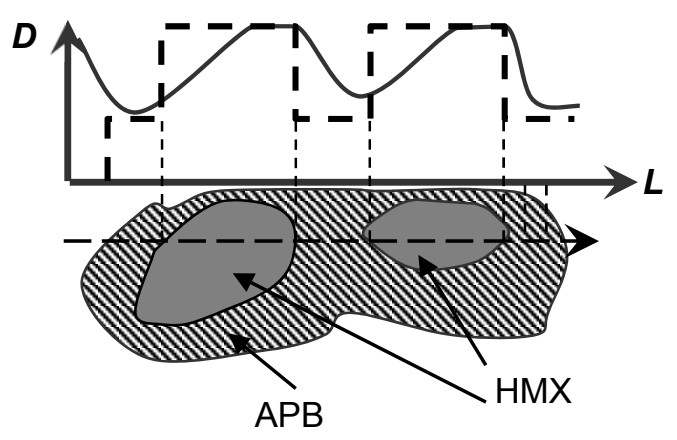

Fig. 2. Propagation of detonation in PBX.

A high filler content in the polymeric matrix may result in an HMX particle 'chain', the detonation through which may outrun the mean detonation velocity defined by Eq. (1). This leading detonation will consequently give rise to a 'nonsmooth' detonation front, which is recorded by the end-face imprint left by the PBX charge on the steel disk. The detonation propagation pattern is schematically displayed in Figure 3.

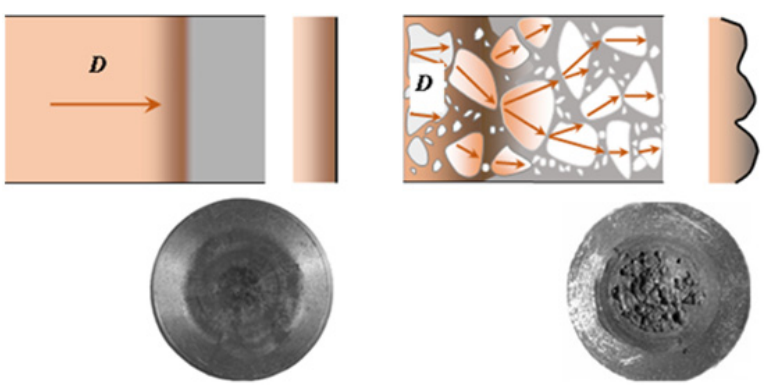

Fig. 3. Detonation propagating in a monocomponent explosive (left) and in a PBX along the percolating cluster (right), and end traces of detonation on metal plates.

The particle 'chain' in 3D formulation represent a percolating cluster [10-11] whose mandatory condition for formation is the sufficient amount of HMX particles with sizes exceeding the critical diameter of detonation under specified conditions.

The 'percolation effect' has consequently revealed and has proved the possibility of controlling the detonation velocity and hence the dynamics of explosion energy release by varying the filler particle size in PBXs.

\subsection{Relationship between PBX acceleration ability and particle sizes of HMX and aluminum}

The acceleration ability $\omega$ of an explosive defined as the ability to boost a body adjacent to an explosive charge is the most crucial factor of practical efficiency. The acceleration ability is defined by detonation velocity $D$ and density $\rho$ of an explosive, as reported [13-15]. The highest acceleration ability is exhibited by formulations that consist nearly $100 \%$ of RDX, HMX, CL-20 and other powerful explosives whose detonation performance stems from the high energy density molecules. The opportunities to enhance the acceleration ability through the synthesis of more powerful individual explosives have almost been exhausted - improvement in the energy density of molecules comes amid a sensitivity increase not compatible with technological processing.

The energy density of aluminized explosives measurably surpasses the energy density limit values of for monocomponent explosives. The energy density or the energy potential of explosives is quantitatively expressed through the quantity of heat of explosion $Q$. Incorporating aluminum into an explosive composition enhances calculated values of $Q$ up to two-fold and upwards and favorably affects the blast effect, whereas the detonation velocity and brisance generally decrease [16]. Regarding aluminum additives as applied to acceleration ability, there are different points of view: for instance, some researchers [17] completely deny the possibility of acceleration ability to be enhanced by embedding aluminum into a formulation; the others [1819] demonstrated a considerable (up to $15 \%$ ) increase in 
acceleration ability when HMX or RDX contained $10-15 \% \mathrm{Al}$.

The calculated and experimental results [20-21] show that $10-15 \% \mathrm{Al}$ introduced into HMX enhance the acceleration ability to the limit: the projectile velocity increases by $2-4 \%$, whereas the heat of explosion has a $25-30 \%$ increase.

The use of percolation effect in PBXs as the way to control the detonation velocity, according to the commonly accepted considerations on $\omega=\mathrm{f}(\rho, D)$, predetermines the possibility of substantially improving the acceleration ability of PBXs.

The acceleration ability of PBX formulations comprised of $\mathrm{HMX} / \mathrm{APB} / \mathrm{Al}$ was examined herein as a function of the filler particle size by the procedure shown in Figure 1.

Varying the particle size of HMX and Al in PBXs with the component ratio and composition density being unchangeable was found to allow the acceleration ability to be effectively controlled from the minimum value of $2140 \mathrm{~m} / \mathrm{s}$ to maximum $2600 \mathrm{~m} / \mathrm{s}$. The latter value is achieved when the formulation contains $10 \mathrm{wt} \% \mathrm{Al}, 20$ wt.\% polymer binder, and two-fraction HMX at a ratio of coarse $(315-700 \mu \mathrm{m})$ to fine fraction (specific surface area $3000 \mathrm{~cm}^{2} / \mathrm{g}$ ) of about 5 to 2 [22]. Note that the acceleration ability of a maximally pressed HMX charge comprising $2.5 \%$ binder does not exceed $2350 \mathrm{~m} / \mathrm{s}$ when tested by the same procedure.

The possibility of enhancing the acceleration ability by varying the solid particle size in PBXs under examination is explained from our point of view by the particular structure of such explosives and by the mechanism through which the energy is released and transmitted to the projectile body. The structure is peculiar because it has two physically heterogeneous systems - an APB and HMX capable of self-detonation - and because the metal fuel particles are in close contact with the APB.

In the context of assumptions that the detonation wave propagates along the percolating cluster, the acceleration process can qualitatively be described by the following postulates.

The projectile body can accelerate as long as the gas pressure behind the body is higher than that before it, that is, the acceleration is defined by both the detonation product pressure and detonation product action time.

The detonation products of composite explosives do not intermix directly in the detonation wave and in the area nearest to it [23-24], and the reaction zone represents a kinetically unbalanced volume in which mass velocity gradients of a few hundred meters per second occur [25]. The propagation of detonation wave will bring the detonation plume out to the interface with the projectile body before all reactions within the explosive are complete, thereby providing the starting acceleration of the body. This starting acceleration will obviously be smaller than that upon approach of a flat detonation front, but the projectile body will persist in the action zone of products of so-called secondary reactions whereby the time the projectile body is exposed to detonation products will increase. The mass velocity gradients originating in the detonation wave promote a fast oxidation of the metal fuel both due to the protective oxide films being separated mechanically from the particle surface and due to the unreacted products intermixing intensively.

\subsection{Analysis of potential energy of PBX conversion into acceleration performance}

The conversion coefficient of the energy potential into acceleration performance in cylinder tests [14] can be estimated by the equation:

$$
K_{m}=\frac{E}{q}
$$

where $K_{m}$ is the conversion coefficient of the energy potential into the acceleration ability of the explosive; $E$ is the kinetic energy of the projectile body $(\mathrm{kJ})$ :

$$
E=\frac{M \omega^{2}}{2}
$$

where $M$ and $\omega$ are the weight $(\mathrm{kg})$ and velocity $(\mathrm{m} / \mathrm{s})$ of the projectile body, respectively;

$$
q=Q \cdot C
$$

$C$ is the weight of the charge to throw the body $(\mathrm{kg}) ; Q$ is the energy potential of the explosive $(\mathrm{kJ} / \mathrm{kg})$.

Table 2. Conversion coefficient of the explosive energy potential into acceleration performance.

\begin{tabular}{|l|c|c|c|c|c|}
\hline $\begin{array}{c}\text { Composition, } \\
\text { (wt.\%) }\end{array}$ & $\begin{array}{c}\boldsymbol{\rho} \mathbf{g} / \mathbf{c m} \\
\mathbf{3}\end{array}$ & $\begin{array}{c}\boldsymbol{Q}_{\mathbf{m a x}}, \\
\mathbf{k J} / \mathbf{k g}\end{array}$ & $\begin{array}{c}\mathbf{q}, \\
\mathbf{k J}\end{array}$ & $\begin{array}{c}\boldsymbol{E}, \\
\mathbf{k J}\end{array}$ & $K_{m}=\frac{E}{q}$ \\
\hline $\begin{array}{l}\text { HMX } \\
(100)\end{array}$ & 1.91 & 6270 & 37.6 & 22.5 & 0.60 \\
\hline $\begin{array}{l}\text { HMX/Al } \\
(88 / 12)\end{array}$ & 1.97 & 7920 & 49.1 & 24.2 & 0.49 \\
\hline $\begin{array}{l}\text { CL-20 } \\
(100)\end{array}$ & 2.04 & 6700 & 43.0 & 25.7 & 0.60 \\
\hline $\begin{array}{l}\text { CL-20/Al } \\
(90 / 10)\end{array}$ & 2.10 & 8040 & 53.1 & 26.7 & 0.50 \\
\hline $\begin{array}{l}\text { HMX/IPB } \\
\text { 98/2) }\end{array}$ & 1.84 & 6100 & 45.9 & 25.8 & 0.56 \\
\hline $\begin{array}{l}\text { HMX/APB } \\
(78 / 22)\end{array}$ & 1.77 & 6150 & 45.3 & 22.2 & 0.49 \\
\hline $\begin{array}{l}\text { HMX/APB/Al } \\
(70 / 20 / 10)\end{array}$ & 1.84 & 7540 & 56.7 & 31.6 & 0.56 \\
\hline \multicolumn{7}{|l|}{ Note : APB - active polymeric, IPB - inert polymeric binder } \\
\hline
\end{tabular}

The evaluation of $q$ by the end-face throwing technique requires the knowledge of the 'active' explosive charge weight, the notion of which is given in [14]:

$$
C_{a}=\frac{2}{3} \pi r_{0}^{3}=\frac{1}{12} \pi d^{3} \rho_{0},
$$

where $C_{a}$ is the active weight, $r_{0}$ is the radius, $l$ is the length and $\rho_{0}$ is the density of the explosive charge.

Eq. (5) is applicable only to a shell-free charge because a massive shell requires that its strength properties are taken account of.

As the energy potential $Q$ of the explosive, it is reasonable to use the maximum heat of explosion $Q_{\max }-$ the energy quantity that corresponds to the most highly 
thermic reactions upon decomposition of the explosive and is equivalent to the maximum entropy. $Q_{\max }$ is an explosive constant because it is defined only by the chemical composition of an explosive. Equations for estimating $Q_{\max }$ are given in [14].

The estimation results for $K_{m}$ by Eqs. (2-5), as reported in [26], are summerized in Table 2. The potential energy of mono-component explosives can be converted into acceleration performance to the greatest possible extent of $60 \%$, whereas the explosion energy conversion into acceleration of the projectile body decreases to $50 \%$ and downwards with added Al. The energy intake by the projectile body can be enhanced to $56 \%$ by optimizing the particle size distribution in PBXs.

\section{Conclusion}

In this study on detonation performance of PBXs, the detonation velocity was found to depend considerably on the filler particle size - within more or less $500 \mathrm{~m} / \mathrm{s}$ of the mean value. It is assumed to be due to different possible mechanisms for detonation front propagation in PBXs: if the filler particle sizes do not reach the critical diameter of detonation, the PBX detonates as a homogeneous explosive to generate a classical 'smooth' front. As the filler particles increase in size, they can produce percolating clusters, along which the leading detonation forms a complex front pattern. In-depth studies of the described phenomenon open the door to controlling the detonation performance of PBXs and also make it possible:

- to control the detonation velocity of melt-cast PBX composites up to $\pm 10 \%$ of the mean value by only varying the filler particle size, without modifying the explosive formulation;

- to develop approaches to compounding melt-cast composite explosives that can increase the energy conversion of aluminized explosives into acceleration performance from $45-50$ to $56 \%$;

- to design composite explosives $10-12 \%$ superior to all the known counterparts in acceleration ability.

\section{References}

1. R. Meyer, J. Kohler, A. Homburg, Explosives. Sixth Edition (Wiley-VCH, 2007)

2. Military Explosives (TM-9-1300-214, Headquarters department of the army, Washington, 1990)

3. G. Antić, V. Džingalašević, M. Stanković, Z. Borković, Sci. Tech. Rev. 56, 3-4, 38 (2004)

4. H.G. Ang, Energetic polymers: binders and plasticizers for enhancing performance (Wiley$\mathrm{VCH}, 2012$ )

5. V.N. Kizhnyaev, T.V. Golobokova, F.A. Pokatilov, L.I. Vereshchagin, Y.I. Estrin, Chem. Heterocyc. Compd. 53, 6/7, 682 (2017)

6. G.S. Khodakov, Russ. J. Gen. Chem. 47, 2, 33 (2003)
7. P. Gondret, L. Petit, J. Rheol. 41, 6, 1261 (1997)

8. V.F Komarov., G.V. Sakovich, M.V. Kazutin, N.I. Popok, A.B. Zhenikhov, Energetic Materials: Performance and Safety. 36th Inter. Annual Conf. of ICT (Karlsruhe, 2005)

9. V.F. Komarov, M.V. Kazutin, N.I. Popok, G.V. Sakovich, Vzryvnoye Delo - NauchnoTekhnicheskiy Sbornik [in Russian], 98/55, 173 (2007)

10. M.V. Kazutin, V.F. Komarov, F.V. Sakovich, N.I. Popok, Polzunovskiy Vestnik, 3, 70 (2008)

11. N.I. Popok, V.F. Komarov, M.V. Kazutin, A.A. Averin, Current Problems in Technical Chemistry: Proc. All-Russ. Sci. Tech. And Method. Conf. (Kazan, 2009)

12. V.F. Komarov, N.I. Popok, G.V. Sakovich, M.V. Kazutin, A.G. Vakutin, A.A. Averin, Advances in Specialty Chemistry and Chemical Engineering: Proc. All-Russ. Sci. Techn. Conf. 75th Birthday of the Fuculty of Engineering Chemistry of Mendeleev University, (Moscow, Mendeleev University, 2010)

13. V.F. Komarov, G.V. Sakovich, M.V. Kazutin, N.I. Popok, Russ. Phys. J, 6, 81 (2006)

14. L.P. Orlenko Physics of Explosion (Moscow, FIZMATHLIT, 2002)

15. V.Yu. Davydov, L.V. Dubnov, A.M. Grishkin, Combust. Explos Shock Waves, 28, 4, 413 (1992)

16. A.M. Grishkin, L.V. Dubnov, V.Yu. Davydov, Yu.A. Levishina, T.N. Mikhailova, Combust. Explos Shock Waves, 29, 2, 239 (1993)

17. V.I. Pepekin, S.A. Gubin, Combust. Explos Shock Waves, 43, 1, 84 (2007)

18. V.Yu. Davydov, V.V. Kozmerchuk, E.Yu. Muryshev, I.D. Golavlev, Combust. Explos Shock Waves, 24, 3, 96 (1988)

19. V.Yu. Davydov, A.M. Grishkin, E.Yu. Muryshev, Combust. Explos Shock Waves, 29, 2, 109 (1993)

20. M.N. Makhov Energetic Materials: Performance and Safety. 36th Inter. Annual Conf. of ICT (Karlsruhe, 2005)

21. M.N. Makhov, V.I. Arkhipov Energetic Materials: Characterisation and Performance of Advanced Systems. 38th International Annual Conference of ICT (Karlsruhe, 2007)

22. G.V. Sakovich, V.F. Komarov, N.I. Popok, M.V. Kazutin. RU Patent No 2382022 (18 April 2008)

23. N.V. Kozyrev, P.M. Brylyakov, Ch.S. Sen, M.A. Stein, Doklady Akademii Nauk USSR [in Russian], 314, 4, 889 (1990)

24. A.P. Yershov, N.P. Satonkina $V$ Int. Conf. Zababakhin's Scientific Readings (Snezhinsk, 1999)

25. D.A. Medvedev, A.P. Yershov, A.L. Kupershtokh, Continuum Dynamics, 120, 93 (2002)

26. M.V. Kazutin, V.F. Komarov, N.I. Popok, A.G. Knyazeva, Polzunovskiy Vestnik, 4-1, 92 (2010) 